\title{
GAIA Level 2 Assessment of Insufficient Cervix
}

National Cancer Institute

\section{Source}

National Cancer Institute. GAIA Level 2 Assessment of Insufficient Cervix. NCI Thesaurus. Code C127954.

GAIA Level 2 Assessment of Insufficient Cervix is defined by two criteria: first, the following three requirements must be met: a) Presentation between 16 and 23 6/7 weeks gestation; b) Advanced cervical dilation greater than two centimeters, resulting in either treatment with a cerclage (cervical stitch) or preterm delivery; c) less than or equal to four contractions per hour as documented by a tocodynometer, meaning the patient is not in preterm labor; second, dilation of the internal cervical os greater than two centimeters as determined by digital examination. 